\title{
A QUÍMICA NEWTONIANA
}

\author{
Ronei Clécio Mocellin \\ Université Paris X, 200, Avenue de la République, 92001 Nanterre - France
}

Recebido em 4/10/04; aceito em 27/7/05; publicado na web em 20/1/06

\begin{abstract}
THE NEWTONIAN CHEMISTRY. The work of Newton exerted a profound influence on the development of science. In chemistry this newtonian influence was present in Query 31 of Newton's Optics. However, the incursion of Newton's thought into chemistry brought upon the chemists an epistemological question, that of the nature of their discipline. Would chemistry be a discipline in its own right, or simply a branch of physics? In this work we present the newtonian program for chemistry, as well as the reaction of traditional chemists to it. We conclude by proposing that Lavoisier carried through a synthesis between newtonian methodology and the singularity of traditional chemistry.
\end{abstract}

Keywords: Newton; theory of affinity; Lavoisier.

\section{INTRODUÇÃO}

A obra de Newton fundamentou programas de pesquisa que transcenderam os limites das ciências físico-matemáticas. Várias outras ciências estabeleceram cânones epistêmicos que tinham na metodologia newtoniana a orientação para suas investigações.

Na ciência química a incursão do pensamento newtoniano deuse através da teoria das afinidades, que procurava explicar aquelas reações que hoje denominamos de simples e dupla-troca. Todavia, essa incursão trouxe ao universo dos químicos uma questão epistemológica de extrema importância, a da natureza de sua disciplina. Seria a química uma ciência singular? Através da descrição da construção de tabelas de afinidade, bem como de sua interpretação teórica, pretendemos identificar o embate entre as consequiências epistêmicas das idéias de Newton e a reivindicação de singularidade da ciência química, fornecida pela tradição aristotélica.

Neste trabalho apresentamos a utilização da metodologia newtoniana pela química desde um ponto de vista histórico-epistemológico, ou seja, procuramos reconstruir as implicações epistêmicas que essa metodologia trouxe à ciência química a partir dos textos originais, embora utilizando termos desenvolvidos pela moderna epistemologia da ciência. É o caso da noção epistemológica de mudança paradigmática, proposta pelo físico-historiador T. S. Kuhn (1922-1996), que utilizamos não no sentido de exemplificar a epistemologia kuhniana, mas apenas com o objetivo de otimizar a compreensão de um processo de produção de conhecimento científico.

Nosso principal objetivo será descrever o programa de pesquisa levado a termo pelos químicos newtonianos, apontando a reação dos químicos tradicionais às conseqüências epistemológicas desse programa. Para atingirmos nosso intento começaremos apontando as origens da interpretação newtoniana para as reações químicas. A seguir, apresentaremos os resultados empíricos obtidos em experimentos guiados pela metodologia newtoniana, bem como as conseqüências epistêmicas da adoção dessa metodologia. Finalizaremos apresentando uma possível síntese lavoisieriana, que ofereceu uma singularidade disciplinar para a química, tendo como base uma metodologia newtoniana.

*e-mail: r.cleciomocellin@gmail.com
Julgamos que esse tipo de trabalho histórico-epistemológico pode contribuir para o ensino da ciência, pois tem por objetivo descrever os processos de produção de conhecimento e não o de apresentar uma linearidade que justifique um determinado conceito atualmente aceito.

\section{A QUESTÃO 31}

Isaac Newton (1642-1727) constituiu um dos pontos altos da revolução científica, iniciada por Galileu e Copérnico, e fundou um novo paradigma científico que, pelo menos na física, permaneceu hegemônico até o início do século XX. Contudo, não pretenderemos descrever a obra newtoniana, mas apenas destacar como essa obra teve implicações para o desenvolvimento da ciência química.

Em 1704, Newton publicou a sua Óptica que, ao contrário dos Principia, não tratava da matemática dos movimentos planetários, mas do estudo dos fenômenos ópticos, elétricos, magnéticos, biológicos, geológicos e das mutações químicas.

A Óptica, assim como os Principia, estava dividida em três partes. Na primeira, Newton apresentou uma série de definições e axiomas que davam forma aos princípios gerais da óptica. A seguir, enunciou as proposições e os teoremas que se referiam à óptica geométrica e, também, à doutrina da composição e dispersão da luz branca, à aberração das lentes, ao arco-íris e à classificação das cores. Na segunda, traçou considerações sobre as cores, os anéis de interferência e a interferência que a luz sofria ao atravessar as lâminas. Na terceira parte, descreveu uma série de experimentos sobre a difração e as franjas coloridas que se produzem na presença de obstáculos miúdos e de lâminas cortantes ${ }^{1}$.

No entanto, Newton reservou os temas de caráter mais especulativo para o final da Óptica, onde propôs uma série de questões ou problemas ("queries") que careciam de respostas. Não deu respostas conclusivas a essas questões, mas sugeriu soluções provisórias que serviram para demarcar um campo de pesquisas.

O número de questões aumentava a cada edição da Óptica. Na edição de 1704 eram 16, na tradução latina de 1706 passaram a 23, e na edição de 1717 foram para 31. Nas últimas questões, Newton tratou de uma série muito ampla de assuntos, indo desde a existência do vácuo, da composição atômica da matéria, das forças elétricas que mantinham os átomos unidos entre si, da insuficiência das causas mecânicas para explicar o universo, das mutações químicas, até 
considerações de caráter teológico. Contudo, em face de nosso objetivo, vamos descrever apenas a questão que interessava mais diretamente à ciência química, a questão 31 da edição de 1717 .

$\mathrm{Na}$ questão $31^{2}$, Newton se questionava sobre a natureza do princípio que regia as atrações químicas, especulando que essas atrações ocorriam por intermédio de forças de atração semelhantes à de gravidade. Segundo Newton:

"Não têm as partículas dos corpos certos poderes, virtudes ou forças por meio dos quais elas agem à distância não apenas sobre os raios de luz, refletindo-os e inflectindo-os, mas também umas sobre as outras, produzindo grande parte dos fenômenos da Natureza? Pois sabe-se que os corpos agem uns sobre os outros pelas ações da gravidade, do magnetismo e da eletricidade; e esses exemplos mostram o teor e o curso da natureza, e não tornam impossível que possa haver mais poderes além desses. Porque a natureza é muito consoante e conforme a si mesma. Não examino aqui o modo como essas atrações podem ser efetuadas. O que chamo de atração pode-se dar por impulso ou por algum outro meio que desconheço. Uso esta palavra aqui apenas para expressar qualquer força na qual os corpos tendem um para o outro, seja qual for a causa".

Essas palavras, além de expressarem a convicção de Newton em expandir sua metodologia, revelam um aspecto da teoria de Newton que foi muito criticado pelos cartesianos e leibnizianos do continente. Os cartesianos, por ex., acusavam Newton de não ter determinado a causa mecânica de suas forças, e que, portanto, sua teoria não seria verdadeiramente mecanicista. A filosofia mecanicista havia abolido qualquer referência a princípios cuja causa não fosse de natureza mecânica, e seus seguidores consideravam as forças newtonianas uma re-introdução de "causas animistas", ou "princípios ocultos".

Newton admitia que desconhecia a causa da força de gravidade, e de outras semelhantes a ela, e também que não acreditava que essa causa fosse de natureza mecânica. Todavia, embora atribuísse a causa da gravidade a "princípios ativos", esclarecia que esses princípios nada tinham a ver com as "causas ocultas" dos aristotélicos. Segundo Newton²:

"Dizer que cada espécie de coisa é dotada de uma qualidade oculta particular, pela qual age e produz efeitos sensíveis, é nada dizer. Mas deduzir dos fenômenos da natureza dois ou três princípios gerais de movimentos, e em seguida observar como as propriedades de todos os corpos e os fenômenos emanam destes princípios constatados, será dar um grande passo na ciência, ainda que as causas destes princípios permaneçam ocultas".

Contudo, transcende nossos objetivos discutir aqui as divergências filosóficas que existiam entre o pensamento newtoniano e o das demais correntes filosóficas de seu tempo. Aqui, interessanos a epistemologia da química, e por isso será pertinente descrever como a ciência química foi influenciada pelo pensamento newtoniano ${ }^{3-5}$.

Afirmar que a ciência química recebeu influência da obra newtoniana é dizer pouco, uma vez que essa influência também foi estendida às demais disciplinas científicas. No entanto, ao menos na química, essa influência newtoniana pode ser descrita através de um exemplo concreto: a teoria das afinidades. É certo que o conceito de afinidade entre duas espécies químicas já era discutido desde a antiguidade; contudo, no século XVIII, esse conceito foi interpretado segundo critérios newtonianos, como revelam as palavras do químico C. L. Berthollet (1748-1822) ${ }^{6}$ :

"As forças que produzem os fenômenos químicos são todas derivadas da atração mútua das moléculas à qual se deu o nome de afinidade, para distinguir da atração astronômica. É provável que uma e outra não sejam senão uma mesma propriedade".

O programa de pesquisa sugerido por Newton demonstra seu desejo de encontrar leis que quantificassem matematicamente as transformações que ocorriam no microcosmo, leis semelhantes àquelas que ele próprio havia encontrado para o macrocosmo. Para alcançar essas leis, Newton argumentava que seria preciso começar por saber que substâncias se atraíam, e quais se repeliam, bem como o grau de atração e de repulsão. Vejamos um exemplo dessa metodologia newtoniana para o estudo da química. Segundo Newton ${ }^{2}$ :

"Quando o sal de tártaro [carbonato de potássio, $\mathrm{K}_{2} \mathrm{CO}_{3}$ ] corre per deliquium [liquefaz-se], derramado na solução de qualquer metal, precipita este último e o faz cair no fundo do líquido na forma de lama, não prova isto que as partículas ácidas são atraídas mais fortemente pelo sal de tártaro do que pelo metal e, pela atração mais forte vão do metal para o sal de tártaro? Assim, quando uma solução de ferro em aqua fortis [ácido nítrico, $\mathrm{HNO}_{3}$ ] dissolve o lapis calaminaris [carbonato de zinco, $\mathrm{ZnCO}_{3}$ ] e solta o ferro, ou uma solução de cobre dissolve o ferro nela mergulhado e solta o cobre, ou uma solução de prata dissolve o cobre e solta a prata, ou uma solução de mercúrio em aqua fortis derramada sobre o ferro, o cobre, o estanho ou o chumbo dissolve o metal e solta o mercúrio, não prova isto que as partículas ácidas da aqua fortis são atraídas mais fortemente pelo lapis calaminaris do que pelo ferro, e mais fortemente pelo ferro do que pelo cobre, e mais fortemente pelo cobre do que pela prata, e mais fortemente pelo ferro, cobre, estanho e chumbo do que pelo mercúrio? E não é pela mesma razão que o ferro necessita de mais aqua fortis para dissolvê-lo do que o cobre, e o cobre mais do que os outros metais; e que, de todos os metais, o ferro é o mais facilmente dissolvido e o mais propenso a enferrujar, e, depois do ferro, o cobre?"

Entretanto, antes de apresentar os resultados empíricos a que os químicos chegaram com sua força de afinidade, cabe ressaltar que, a partir da segunda metade do século XX, se tomou conhecimento da relação que Newton tinha com a alquimia, o que revelou um Newton muito mais próximo da química.

A face alquimista de Newton começou a ser desvendada a partir de 1936, com a compra dos manuscritos alquimistas de Newton por Lorde Keynes, o economista, que depois de lê-los declarou ${ }^{7}$ :

"Newton não foi o primeiro no século da Razão, foi o último dos Babilônios e Sumérios, o último grande espírito que penetra o mundo do visível e do espírito com os mesmos olhos que os que começaram a edificar o nosso patrimônio cultural há pouco mais de dois mil anos".

Esta declaração causou constrangimento àqueles que tinham em Newton o modelo de cientista positivo, e atraiu a atenção dos historiadores sobre o tema. Na medida que esses manuscritos foram sendo divulgados, percebeu-se que a relação de Newton com a alquimia era bem mais profunda do que se imaginava. Historiadores como Westfall e Dobbs sugeriram que Newton almejava uma síntese filo- 
sófica mais ampla entre os fenômenos macroscópicos e microscópicos. A alquimia, ao fornecer evidências das "virtudes" e dos "poderes" das partículas materiais, contribuía para essa síntese cosmológica ainda mais ampla que aquela oferecida nos Principia. O historiador McGuire também concorda com esta posição, e afirma que ${ }^{8}$ :

"Na tradição do pensamento renascentista, representado na Inglaterra pelos platonistas de Cambridge, uma das preocupações centrais de Newton foi a existência do espiritual na natureza. Além da existência da gravitação, Newton via na larga gama de fenômenos químicos e bioquímicos evidência do espiritual [...] Esses movimentos "vitais" inclinavam sua mente para a possibilidade de um sistema baseado em leis categoricamente diferentes dos axiomáta dos Principia: uma filosofia natural do domínio do oculto, baseado nas microforças. Embora Newton, por algum tempo, tenha considerado essas forças como sendo elétricas e magnéticas, ou geradas pela ativação de partícula de luz, a atividade química permaneceu a melhor evidência para determinar suas características".

Esse Newton alquimista pode parecer anedótico para os historiadores que se interessam por astronomia ou pela ciência do movimento. Porém, para os historiadores que se interessam pela química, o Newton alquimista é fundamental, pois representa uma tentativa de descrever as transformações químicas segundo rígidos padrões metodológicos.

Não vamos nos estender sobre uma possível interpretação alquímica da obra de Newton. Nosso objetivo é mais modesto, de modo que restringiremos nossa análise às implicações do resultado empírico e conceitual, obtido pela teoria que estabelecia um elo entre Newton e a ciência química.

Para concluir, cabe um balanço da incursão newtoniana pela ciência química. Essa incursão pode ser interpretada pelo historiador de duas maneiras?

\begin{abstract}
“a questão 31 pode ser interpretada como uma tentativa de incorporação da química pela física; mas também pode ser lida de uma maneira que faz Newton restituir aos químicos o direito de falar de "poder", ou de "potência" dos reagentes, dando um sentido à sua prática, às suas operações, sentido este negado pela ciência puramente mecanicista”.
\end{abstract}

A primeira leitura da questão 31 foi própria daqueles que não consideravam a química uma ciência digna de figurar entre as "ciências clássicas". Sobre esta posição são reveladoras as palavras de Fontenelle (1699) ${ }^{6}$ :

"A química, através de operações visíveis, divide os corpos em certos princípios grosseiros e palpáveis, sais, enxofres, etc. mas a física, por especulações delicadas, age sobre os princípios como a química faz sobre os corpos; ela divideos noutros princípios ainda mais simples, em pequenos corpos em movimento e representados duma infinidade de maneiras... O espírito da química é mais confuso, mais embaraçado; assemelha-se mais às misturas, onde os princípios estão mais embrulhados uns nos outros: o espírito da física é mais simples, mais solto, enfim ele vai até as primeiras origens, o outro vai até os fundamentos".

A segunda leitura revela que o pensamento newtoniano também foi incorporado na tradição dos químicos, fornecendo a esta tradição padrões metodológicos semelhantes aos da astronomia.

\section{AS TABELAS DE AFINIDADE}

Em 1718, na França, É. Geoffroy (1672-1731), professor do Collège de France, apresentou sua Tabela das Diferentes Relações Observadas entre Diferentes Substâncias, que constituía uma interpretação empírica da questão 31.

Nessa tabela, Geoffroy interpretou um conjunto de reações químicas, que hoje denominamos de deslocamento, ou melhor, de reações de simples e de dupla troca $(\mathrm{A}+\mathrm{BC} \rightarrow \mathrm{AC}+\mathrm{B}, \mathrm{e}, \mathrm{AB}+$ $\mathrm{CD} \rightarrow \mathrm{AD}+\mathrm{CD}$, respectivamente)

Na tabela de Geoffroy, encontram-se 16 substâncias que encabeçam 16 colunas. Em cada coluna, a afinidade para com a substância na cabeça da coluna decresce de cima para baixo, de modo que quando duas substâncias com alguma tendência a se combinarem estão reunidas e encontram uma terceira com afinidade maior com alguma das primeiras, ela se combina com alguma destas, deixando livre a outra9 (Figura 1).

Traduzindo a primeira coluna para uma linguagem moderna, podemos entender melhor o assunto do qual a tabela tratava. A primeira coluna refere-se às reações ácido-base, na qual se acompanha a ordem decrescente de reatividade dos ácidos frente aos álcalis, aos óxidos metálicos e aos metais. Assim, um ácido reagiria preferencialmente com álcalis fortes (bases fortes, $\mathrm{NaOH}, \mathrm{KOH}$, ...), seguido dos álcalis fracos $\left(\mathrm{NH}_{4} \mathrm{OH}, \ldots\right)$, dos óxidos metálicos e dos metais.

Os ganhos empíricos trazidos pela tabela de Geoffroy foram relevantes. Ela permitiu, por ex., agrupar uma série de reações químicas em um quadro econômico, oferecendo aos químicos um importante instrumento pedagógico. No entanto, essa incorporação empírica das forças newtonianas colocou aos químicos um problema relativo à própria natureza de seu trabalho. Este problema estava ligado a uma questão ontológica, ou seja, sobre o conjunto das coisas que se admitiam serem próprias das ciências químicas.

Em uma linguagem epistemológica atual, devida a Quine, poderíamos dizer que a diferença entre os químicos tradicionais e os químicos newtonianos estava no conjunto de entidades aceitas por cada um destes grupos. Em ambos os grupos havia produção de conhecimento, uma vez que o valor de verdade de cada um se remetia às próprias entidades de sua ontologia, contudo, esse conhecimento não se remetia a entidades comuns. $\mathrm{O}$ caminho indicado pelos newtonianos remetia os interesses da ciência química ao universo das relações que o corpo químico estabelecia com sua vizinhança. Portanto, não fazia sentido para um químico newtoniano descrever um corpo químico isoladamente, assim como não fazia sentido para um astrônomo descrever um astro isento de suas relações com os demais corpos celestes. Seguindo esse caminho, os químicos seriam levados a abandonar a noção tradicional de corpo químico, pois, na medida em que se assumia que as reações químicas podiam ser compreendidas a partir de forças newtonianas, os corpos em si mesmos se tornavam inertes como os planetas ${ }^{10}$.

Essa idéia se opunha a uma tradição química que vinha desde a antiguidade, e que remetia seus juízos a qualidades que singularizavam as substâncias químicas. A substância química, nessa tradição, era o sujeito cuja reação exprimia apenas a qualificação. Na química newtoniana, ao contrário, o corpo químico não era mais um sujeito senão por aproximação de linguagem. O único verdadeiro sujeito era o conjunto dos corpos em presença e com interações recíprocas. Assim, não era possível atribuir a força do ácido nítrico a ele mesmo, depois de o ter ilustrado com algumas reações típicas, e sim defini-la a partir de um conjunto de reações possíveis ${ }^{6}$. Ou seja, enquanto na química tradicional se elegia um conjunto de reações para caracteri- 


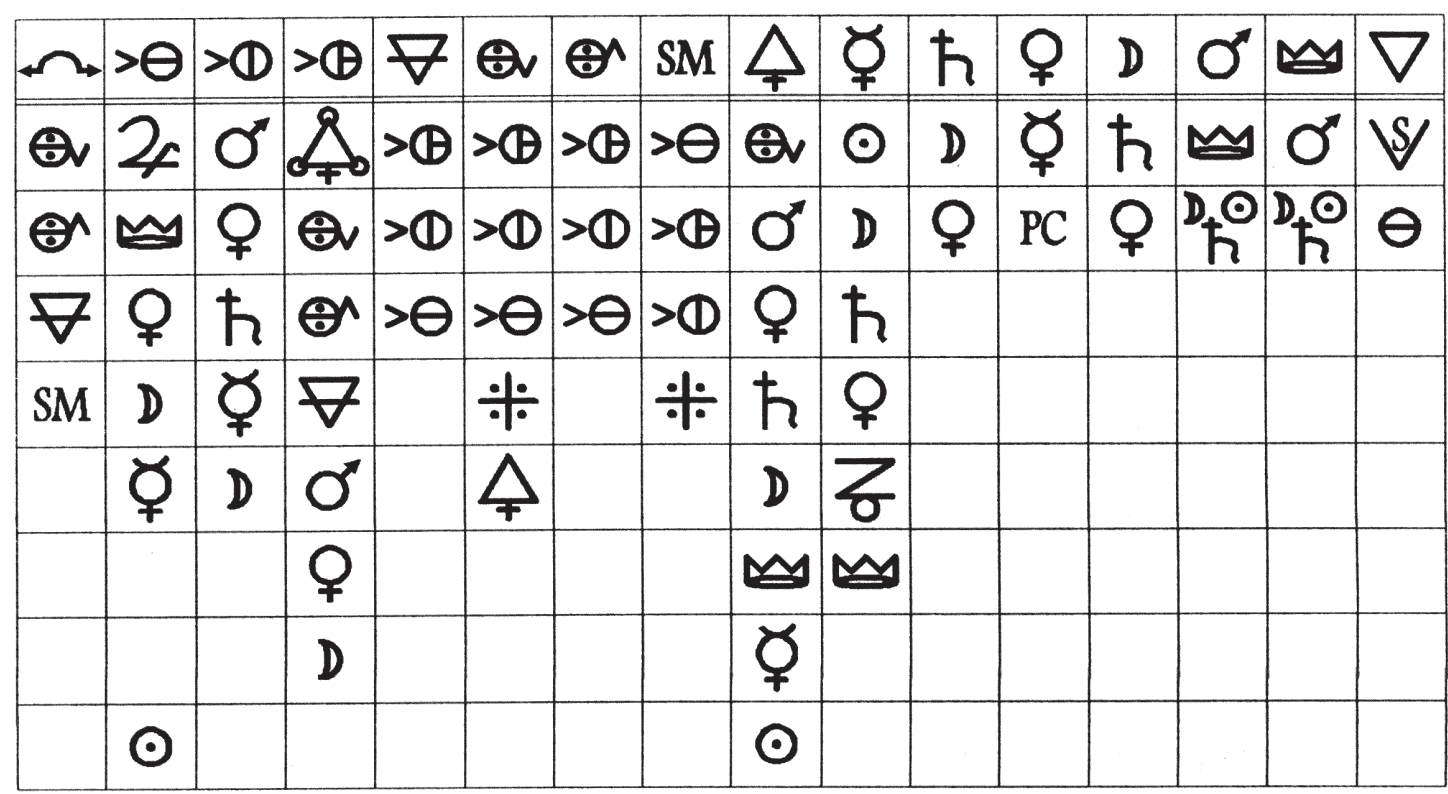

\begin{tabular}{|c|c|c|c|c|c|}
\hline & espíritos ácidos & $\div$ & espirito do vinagre & PC & pedra calamina \\
\hline$>\theta$ & $\begin{array}{l}\text { ácido de sal } \\
\text { marinho (HCl) }\end{array}$ & $\odot$ & ouro & $S$ & $\begin{array}{l}\text { espirito do vinho } \\
\text { (álcool) }\end{array}$ \\
\hline$>0$ & $\begin{array}{l}\text { ácido nitrosado } \\
\left(\mathrm{HNO}_{3}\right)\end{array}$ & & mercúrio & D & prata \\
\hline$>\theta$ & $\begin{array}{l}\text { ácido vitriólico } \\
(\mathrm{H}, \mathrm{SO})\end{array}$ & & cobre & $\underline{M}$ & antimônio \\
\hline Qv & $\begin{array}{l}\text { sal álcali fixo } \\
(\mathrm{NaOH})\end{array}$ & & estanho & 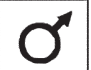 & ferro \\
\hline 8 & $\begin{array}{l}\text { sal álcali volátl } \\
\left(\mathrm{NH}_{3}\right)\end{array}$ & & água & $\sum$ & zinco \\
\hline$\nabla$ & terra absorvente & & enxofre (o mineral) & $\theta$ & sal \\
\hline SM & $\begin{array}{l}\text { substâncias } \\
\text { metálicas }\end{array}$ & & enxofre (o principio) & $\hbar$ & chumbo \\
\hline
\end{tabular}

Figura 1. Diagrama reproduzido da ref. 9, com permissão do autor, que possui o copyright

zar um corpo químico, na química newtoniana todas as reações interessam na descrição desse corpo. Esta diferença fez com que os químicos newtonianos investigassem reações que não eram "interessantes" para um químico tradicional, ou melhor, reações que muitas vezes não produziam o composto esperado, ou ocorriam de modo oposto ao previsto. As reações "interessantes", na verdade, consistiam nas reações que hoje denominamos completas, ou seja, aquelas na qual o produto deixa o meio reacional, ou na forma de precipitado, ou por sua volatilidade. Para os newtonianos, contudo, as reações "interessantes" não eram suficientes para descrever as afinidades, que, no vocabulário newtoniano, passaram a ser chamadas de atrações eletivas.

Essa noção de corpo químico foi contestada por aqueles que defendiam uma singularidade para esses corpos. Foi no quadro teórico tradicional que os químicos fundamentaram suas explicações para as transformações químicas. O médico-químico alemão E. Stahl (1660-1734) apresentou um sistema explicativo que resgatava os "elementos" aristotélicos. Embora não considerasse todos os quatro elementos, preservava a idéia de elemento princípio, portador de qualidade. Stahl foi o principal personagem da quími- ca da primeira metade do século XVIII; sua teoria foi uma resposta "química" à transformação material, oposta ao reducionismo mecanicista e longe das metáforas alquímicas. Assim, os químicos stahlianos procuravam descrever as reações químicas a partir de propriedades que seriam singulares a cada corpo químico. O sistema de Stahl exerceu profunda influência no desenvolvimento da química, sendo considerado por Kant, no prefácio da Crítica da Razão Pura, o sistema responsável por elevar a química ao nível das ciências modernas ${ }^{11}$.

No entanto, essa divergência epistêmica não impediu que os químicos stahlianos utilizassem a tabela de Geoffroy, tendo havido inclusive uma harmonização entre essas duas correntes, oferecida pelo stahliano P. J. Macquer que, em seu livro Elementos de Química (1775), apresentou uma exposição sistemática da doutrina das afinidades. Macquer sublinhou o caráter empírico das tabelas e que os resultados obtidos deveriam ser aceitos independentemente da teoria que sistematizava as práticas experimentais. Assim, Macquer aceitava a ordenação dos compostos químicos de acordo com sua reatividade, mas não as conseqüências derivadas de uma interpretação estritamente newtoniana. Para ele, as transformações 
químicas deveriam ser explicadas recorrendo a elementos que remetessem a propriedades qualitativas distintas.

Mas, apesar dos químicos não-newtonianos adotarem tabelas semelhantes à de Geoffroy, a construção dessas tabelas de afinidade ficou a cargo dos químicos newtonianos. E, para os newtonianos, além de ordenar as substâncias de acordo com sua afinidade relativa, interessava descrever as reações químicas com a mesma precisão que se descreviam os movimentos planetários.

Foram várias as tentativas de quantificar adequadamente as afinidades. Em 1776, por ex., Guyton de Morveau, seguindo o caminho newtoniano, mediu a força mecânica necessária para separar placas de diferentes metais do banho de mercúrio no qual as mesmas flutuavam. Assim, Guyton tentava quantificar a afinidade, atribuindo à relação entre dois corpos, uma medida independente das operações de substituição ${ }^{7}$.

Essa quantificação era relativa e, como tal, podia ser expressa por uma sequiência de números relativos, de modo que, quanto maior o número, maior seria a atração entre as espécies envolvidas. Para mostrar isso, é muito ilustrativo o exemplo extraído da obra do químico brasileiro V. de S. Telles (1764-1804). Aliás, cabe salientar que Telles foi o primeiro químico estrangeiro a utilizar a nova química de Lavoisier, como demonstra seu livro Elementos de Química, publicado em Coimbra no ano de 1788, um ano antes da publicação do Tratado de Lavoisier ${ }^{12,13}$.

Assim, a nova química esteve à disposição dos químicos de língua portuguesa ao mesmo tempo em que esteve aos da língua de Lavoisier. Esta singularidade talvez ofereça um tema interessante para aqueles que procuram analisar a ciência segundo critérios sociológicos, pois permitiria discorrer sobre as possíveis influências que o meio cultural, político e econômico dos respectivos países exerceu sobre o desenvolvimento de uma disciplina científica.

Aqui, só cabe a sugestão de uma possível área de investigação, pois, de Telles nos serviremos apenas do método de previsão de ocorrência de reações regidas por afinidades newtonianas. Telles mencionou tabelas de afinidades entre 8 ácidos e 7 bases, atribuindo valores relativos às afinidades entre estes, permitindo prever a ocorrência, ou não, de reações.

Tabela 1. Tabela dos graus de afinidades expressas por números relativos

\begin{tabular}{cclc}
\hline \multicolumn{2}{l}{ Ácido sulfúrico com } & \multicolumn{2}{l}{ Ácido muriático com } \\
\hline barita & 14 & barita & 12 \\
potassa & 13 & potassa & 11 \\
soda & 12 & soda & 10 \\
cal & 11 & cal & 8 \\
amoníaco & 9 & amoníaco & 7 \\
magnésia & $81 / 2$ & magnésia & 6 \\
argila & 8 & argila & 5 \\
\hline
\end{tabular}

Filgueiras, ao analisar os exemplos sugeridos por Telles, comenta um caso genérico, envolvendo as espécies $A, B, C$ e $D$ :
$A+B \rightarrow A B$
$A+C \rightarrow A C$
Afinidade $=7$
$C+D \rightarrow C D$
Afinidade $=6$
$B+D \rightarrow B D$
Afinidade $=3$
Afinidade $=5$

Assim, como a afinidade que une A e B para formar AB é 7, e a afinidade que une $\mathrm{A}$ e $\mathrm{C}$ para formar $\mathrm{AC}$ é 6 , temos que:

$A B+C \rightarrow$ não ocorre, pois o produto $A C$ que seria formado envolveria uma afinidade relativa 6 , menor, portanto, que a afinidade entre $A$ e $B$, que é 7 .

Reproduzindo um exemplo citado nos Elementos de Química, convertidos para a linguagem moderna, temos:

$$
\begin{array}{ll}
\mathrm{NaOH}+\mathrm{HCl} \rightarrow \mathrm{NaCl} & \text { Afinidade }=10 \\
\mathrm{NaOH}+\mathrm{H}_{2} \mathrm{SO}_{4} \rightarrow \mathrm{Na}_{2} \mathrm{SO}_{4} & \text { Afinidade }=12 \\
\mathrm{Ca}(\mathrm{OH})_{2}+\mathrm{HCl} \rightarrow \mathrm{CaCl}_{2} & \text { Afinidade }=8 \\
\mathrm{Ca}(\mathrm{OH})_{2}+\mathrm{H}_{2} \mathrm{SO}_{4} \rightarrow \mathrm{CaSO}_{4} & \text { Afinidade }=11
\end{array}
$$

a partir desses valores é possível concluir que:

$\mathrm{Na}_{2} \mathrm{SO}_{4}+\mathrm{HCl} \rightarrow$ não reage, pois daria $\mathrm{NaCl}+\mathrm{H}_{2} \mathrm{SO}_{4}=10$

Outras tentativas, semelhantes às de Seabra Telles, foram apresentadas na segunda metade do século XVIII. Contudo, além dos cálculos relativos às atrações, os newtonianos consideravam que o enquadramento das novas descobertas em tabelas de afinidade representava o caminho pelo qual a química deixaria de ser uma prática artesanal, passando a ser uma ciência dedutiva. Tendo este objetivo, o químico sueco T. Bergman trabalhou na construção de tabelas seguindo uma metodologia newtoniana.

Uma vez que aos químicos newtonianos todas as reações interessavam, Bergman se propôs a realizar o maior número delas, a fim de esquematizá-las em tabelas semelhantes à de Geoffroy. Contudo, apesar de apresentarem o mesmo aspecto e de utilizarem a mesma simbologia herdada da tradição alquímica, o trabalho de Bergman assumia abertamente um compromisso newtoniano, transcendendo o limite empírico frisado por Geoffroy, e solidificando, com isso, o programa de transformar a química em ciência através do paradigma newtoniano.

Mas isso não quer dizer que Bergman desejasse reduzir a química à física, mas que as análises das transformações químicas deveriam ser remetidas às forças que atuavam no microcosmo. Nesse aspecto, Bergman seguiu a sugestão do químico stahliano G. F. Venel que, na Enciclopédia, havia requerido um estudo da relação íntima entre os corpos, garantindo, com isso, uma singularidade para esta ciência. Porém, apesar de concordar com Venel quanto aos tipos de afinidade, Bergman divergia deste quanto ao método mais adequado para caracterizar as afinidades propriamente químicas, ou seja, aquelas que permitiriam explicar como a união de dois corpos heterogêneos produzia um terceiro, este homogêneo. Para Venel, esse tipo de afinidade somente poderia ser explicado na medida em que conhecêssemos as propriedades intrínsecas de cada corpo; já para Bergman, as afinidades químicas poderiam ser explicadas de um modo newtoniano, ou seja, a partir da relação que um corpo químico estabelecia com outro corpo químico ${ }^{7}$.

Bergman considerava dois tipos de afinidade: a de agregação, e a de composição. As atrações ou afinidades de agregação envolviam as substâncias homogêneas e correspondiam simplesmente a acúmulo de massa, não caracterizando propriamente uma reação química, ou seja, eram afinidades próprias da mecânica. As atrações de composição, ao contrário, verificavam-se em substâncias heterogêneas, podendo ser atrações eletivas simples ou duplas, caracterizando, portanto, afinidades "verdadeiramente químicas".

As tabelas de Bergman, publicadas de 1775 a 1783, além de incluírem as novas substâncias, também tentavam responder a uma crítica feita pelos adversários stahlianos, a de que a química newtoniana não levava em consideração as peculiaridades do meio reativo, bem como os estágios intermediários, obtidos na reação dos mesmos compostos em condições diferentes. É certo que a resposta de Bergman não satisfez plenamente aos stahlianos, pois enumerou apenas duas condições que deveriam ser levadas em conta ao reali- 
zar uma reação: a via úmida (solução) e a via seca (altas temperaturas). Não considerou, por ex., uma possível reação com a água, ou ainda, a influência da temperatura na reação.

Mesmo assim, Bergman realizou um enorme trabalho, no qual ordenava os milhares de reações possíveis entre 27 ácidos, 8 bases e 14 metais, agrupando-as em 49 colunas, com um duplo registro: em solução e a seco. Bergman considerava a afinidade eletiva entre dois corpos como fixa e totalmente independente de variáveis como, por ex., excesso de reagentes, ou mudanças de temperatura.

As evidências experimentais dessas afinidades "verdadeiramente químicas" eram as reações típicas da tradição, já agrupadas na tabela de Geoffroy. Todavia, essas reações tinham a característica de serem completas, ou seja, de serem reações nas quais os reagentes se transformavam totalmente em produto, o que se dava quando um dos produtos escapava do meio reativo.

Contudo, o programa de Bergman se propunha a realizar todas as reações possíveis, e não apenas as tradicionalmente trabalhadas. Isso levou Bergman a se deparar com um número crescente de reações que não ocorriam de maneira completa, ou ainda, não ocorriam no sentido esperado. Bergman respondia a essas anomalias recorrendo a obstáculos físicos (concentração, temperatura, etc.) que, segundo ele, impediam que as afinidades "verdadeiramente químicas" se manifestassem; porém as anomalias se multiplicavam.

Se há um bom exemplo de mudança paradigmática, segundo a expressão de Kuhn, é sem dúvida o modo como Berthollet vai transformar em regra as anomalias de Bergman. Esta peculiaridade nos permitirá demonstrar o uso da história da ciência na exemplificação de modelos epistemológicos atuais. Porém, antes de apresentarmos uma ambientação histórica de uma mudança paradigmática, cabe um comentário mais detalhado sobre a epistemologia kuhniana.

\section{AS REVOLUÇÕES CIENTÍFICAS}

Durante a primeira metade do século XX, foram levadas a termo diversas investigações acerca das características filosóficas que o conhecimento científico apresentara. Não obstante as divergências filosóficas que tais investigações suscitaram, pode-se dizer que compartilhavam a idéia, amplamente aceita, de que o desenvolvimento das ciências empíricas ocorria por meio de um acúmulo linear do saber.

Em 1962, o físico-historiador T. S. Kuhn publicou A Estrutura das Revoluções Científicas, um livro que apresentava um enfoque alternativo na interpretação do desenvolvimento do conhecimento científico.

Segundo Kuhn, era inaceitável a idéia de que o avanço do conhecimento científico ocorria através de um processo de acúmulo gradual e linear de novas descobertas. Segundo ele, era fruto de uma profunda incompreensão histórica o fato de considerarmos, por ex., que a física de Newton era melhor que a de Aristóteles, pois resolvia problemas pendentes na física dos aristotélicos, ampliando, com isso, nosso conhecimento. Kuhn, ao contrário, defendia que a característica essencial do conhecimento científico, e aquilo que o diferenciava de outras formas de conhecimento, era apresentar um desenvolvimento repleto de descontinuidades e de saltos revolucionários.

Em sua argumentação, Kuhn distinguiu duas formas de fazer ciência: a ciência normal e a ciência extraordinária. Segundo ele, a maior parte da investigação científica praticada pelos pesquisadores resultava de trabalhos realizados durante períodos de ciência normal. Então, era a ciência normal que produzia os blocos que a investigação científica continuamente adicionava ao crescente edifício do conhecimento científico, em um processo cumulativo semelhante ao da visão tradicional.
A existência de períodos de ciência normal somente se tornava possível na medida em que um grupo de cientistas pesquisasse sob orientação de um paradigma.

O surgimento de um paradigma hegemônico ocorria, segundo Kuhn, após um período no qual diversos candidatos buscavam maneiras alternativas de selecionar e solucionar problemas. Nestes períodos, chamados por ele de pré-paradigmáticos, conviviam diversas escolas competidoras, sem que nenhuma delas tivesse a hegemonia do campo de pesquisas considerado. Porém, quando uma dessas escolas triunfava sobre as outras, e conseguia a adesão geral dos pesquisadores daquela área de estudos, sua maneira de delimitar e resolver um problema era assumida como exemplar, ou como modelo de investigação naquele campo, ou seja, como paradigma para quem quisesse fazer ciência.

Assim, na visão de Kuhn, o surgimento de uma disciplina científica era caracterizado como o momento de fundação desta disciplina, momento provocado devido à emergência de um primeiro paradigma. Esta fundação disciplinar tanto podia ocorrer a partir de um arcabouço herdado da tradição, como através de um início absoluto. Assim, por ex., a astronomia copernicana e a física newtoniana, que suplantaram, respectivamente, a astronomia ptolomáica e a física aristotélica, constituíam exemplos de surgimento de um novo paradigma através de uma "re-fundação" disciplinar. Já o surgimento da lógica aristotélica parece ter sido um caso de surgimento ex nihilo. Porém, em ambas situações, seus protagonistas principais foram considerados fundadores de disciplinas científicas.

Contudo, seja por um início sem precedentes, seja por um novo começo, o estabelecimento de um novo período de ciência normal envolve bem mais que a resolução de um problema particular. Segundo Kuhn, o novo paradigma deve resolver não apenas o problema que o possibilitou existir, mas, sobretudo, deve apresentar uma série de outros problemas ainda não resolvidos, de modo a garantir um campo de investigação promissor para futuros pesquisadores. Por ex., as pesquisas que procuram a determinação daqueles fatos que são particularmente reveladores da natureza das coisas que o paradigma julga existir, ou aquelas que buscam estabelecer novos fatos a partir das predições feitas pela teoria, ou ainda, aquelas voltadas para a própria articulação da teoria, visando determinar constantes físicas, ou leis quantitativas, constituem realizações das promessas de sucesso que um paradigma contém ${ }^{14}$.

A pesquisa normal, que é rígida e não admite novidades, produz novidades que podem pôr em risco a existência do próprio paradigma. Segundo Kuhn, a principal tarefa do pesquisador normal consiste na resolução de quebra-cabeças, problemas sugeridos pelo paradigma, ou seja, seu trabalho procura transformar em realidade as promessas desse paradigma. Porém, muitas vezes, o pesquisador vê suas expectativas frustradas, dando-se conta de que algo saiu errado. Essa frustração da expectativa induzida pela pesquisa orientada por um paradigma Kuhn denominou anomalia. Assim, uma anomalia seria o resultado da própria pesquisa normal e das investigações orientadas pelo paradigma. Porém, com o tempo, essas anomalias podem ser reforçadas e, dependendo da importância dada pelos pesquisadores ao problema em questão, podem levar a ciência normal a um período de crise. Essa crise que, segundo Stengmüller, designa apenas um estado psíquico associado ao grupo de pesquisadores, pode ter desfechos diferentes. Pode ocorrer que, depois de algumas tentativas, o problema seja resolvido no interior do próprio paradigma, ou, se não envolver uma questão central, pode ser deixado de lado para uma futura resolução. No entanto, também pode ocorrer que, devido à importância das questões envolvidas na anomalia, uma solução alternati- 
va, que não segue a orientação da ciência normal, seja apresentada provocando uma revolução científica. Um novo paradigma surge, portanto, não de modo gradual, como fruto do trabalho de uma equipe de peritos, mas, ao contrário, explosivamente, na mente de uma pessoa que mergulhou fundo na crise ${ }^{15}$.

Segundo Kuhn, o antigo e o novo paradigmas mostram-se incomensuráveis, ou seja, não é possível traduzir completamente um no outro. Contudo, este fato fica mais ou menos encoberto, pois o novo paradigma se vale muitas vezes das mesmas expressões usadas pelo paradigma antigo. Porém, a mecânica newtoniana, por exemplo, não pode ser vista como caso-limite da mecânica relativista, pois os conceitos de espaço, tempo, massa, energia significam, nesta última, algo muito diverso do que significavam na primeira. Por isso, a passagem de um paradigma antigo para um novo não se efetua gradualmente, guiado pela lógica e pela metodologia, mas de forma repentina, semelhante àquelas que os psicólogos chamam de mudança de Gestalt ${ }^{14}$.

Devido à variedade de sentidos em que o termo paradigma foi empregado, Kuhn fez algumas reconsiderações, onde reduziu todos os possíveis sentidos de paradigma a apenas dois: um global, abarcando os elementos partilhados por um grupo de cientistas; outro, mais estrito, isolando um gênero particularmente importante desse elemento, do qual faz parte. Ao sentido mais geral de paradigma Kuhn denominou de matriz disciplinar - matriz, porque se compunha de elementos ordenados de vários gêneros, cada um exigindo especificações ulteriores; e disciplinar porque era possessão comum dos praticantes de uma disciplina profissional. Ao sentido mais estrito Kuhn denominou de exemplar, que fazia parte da matriz disciplinar, juntamente com as generalizações simbólicas e os modelos ${ }^{16}$.

Apesar das dificuldades que o emprego do termo paradigma trouxe à epistemologia kuhniana, sua escolha serviu para que Kuhn relacionasse suas idéias com o conceito de jogo, devido a Wittgenstein. Assim, segundo ele, como não existem características necessárias e suficientes para denominar jogo uma atividade humana, também não há condições que permitam diferenciar, de modo rígido, um físico aristotélico, um físico newtoniano ou um físico quântico. Em ambos os casos só existem certos "traços de família"14.

Além disso, o emprego do termo paradigma evitava o emprego da palavra "teoria", utilizada mais como referência a teorias formalizadas à moda dos lógicos. Entretanto, segundo Kuhn, as perspectivas dos lógicos eram antes um empecilho do que uma ajuda quando se tratava de investigar as teorias sob o prisma da história, muito embora a análise lógica fosse parte integrante de um paradigma. Aliás, na visão de Kuhn, quando se fazia filosofia da ciência apenas considerando análises lógicas e metodológicas, as referências feitas à história da ciência remetiam mais àquelas narrativas históricas escritas por cientistas-historiadores do século XIX que, não obstante a importância, estão mais para uma caricatura que para uma descrição detalhada da história de uma determinada disciplina.

Um paradigma, segundo Kuhn, era muito mais abrangente que aquelas noções que admitiam formulação em enunciados: a um paradigma correspondia, no reino dos fenômenos, toda uma coleção de idéias intuitivas básicas - delimitando, em linhas amplas, quais eram, para os pesquisadores, as perguntas que traduziam problemas relevantes e importantes e os métodos de solução que podiam ser vistos como adequados. Mais do que isso: o paradigma geral extravasava os limites do puramente teórico e se confundia com o que entendemos verdadeiro, ou com o que entendemos haver observado. Assim, não teria sentido falar da ciência, mas de formas da ciência, uma vez que tivemos ao longo da história diversas maneiras de atuação científica, tais como a Física de Aristóteles, a Astronomia de Ptolomeu, a Química do flogisto, etc. Desse modo, cada uma dessas ciências surgiu a partir de uma revolução, foi construída durante um período de ciência normal e, finalmente, substituída por outras formas de se fazer ciência ${ }^{15}$.

Com essa maneira alternativa de compreensão do desenvolvimento do conhecimento, as revoluções paradigmáticas de Kuhn, além de fomentarem intensos debates filosóficos, também renovaram o interesse pela história epistemológica da ciência. Porém, aqui, o modelo kuhniano interessa menos como um modelo rígido de análise, e mais como inspiração para realização de trabalho histórico centrado em questões epistêmicas.

\section{AS ANOMALIAS DE BERGMAN}

No programa de Bergman, era necessário estudar todas as reações químicas possíveis, pois só conheceríamos uma substância na medida que investigássemos suas relações com outras substâncias vizinhas. Todavia, durante seu trabalho, Bergman verificou que a maioria das reações não produzia um produto puro, ou até ocorria de modo inverso ao esperado.

As reações incompletas representaram para o programa de Bergman aquilo que Kuhn chamou de anomalia, pois consistiram no reconhecimento de que, de alguma maneira, a natureza violava as expectativas paradigmáticas que governavam a ciência normal. As reações incompletas eram anomalias que perturbavam o esquema geral, não sendo assimiladas por esse esquema. Bergman tentava assimilá-las, ampliando a explicação acerca dos possíveis obstáculos externos, que impediam que a reação formasse um único produto; porém, as anomalias estavam se tornando a regra.

$\mathrm{Na}$ França, Berthollet, também newtoniano, ao trabalhar em um projeto que objetivava aumentar a produção de pólvora para canhão, deparou-se com um fenômeno que considerou muito interessante. Berthollet, empenhado em defender a revolução, transformou o procedimento artesanal de extração do salitre, que tinha por hábito lavar as rochas nitrosas no próprio local de extração, em um processo industrial controlado. Com isso, percebeu que, quanto maior fosse a quantidade de salitre dissolvida, menos eficaz era a lavagem. Preferiu lavar várias vezes, empregando em cada lavagem uma água nova, notando ainda que, a cada lavagem, a extração era menor. Então, concluiu que a tendência de um corpo a se combinar com um outro decrescia proporcionalmente ao grau de combinação já alcançado. Isto significa que a afinidade, em vez de caracterizar um corpo na sua relação com um outro, se tornou uma função do estado físico-químico do meio, e, em particular, da concentração dos reagentes em presença na reação. A afinidade se tornava, assim, totalmente newtoniana, não havendo mais a distinção entre afinidade física e afinidade química.

Em 1800, acompanhando a expedição de Napoleão ao Egito, Berthollet se deparou com um fenômeno que confirmava suas convicções sobre a afinidade: um "lago de sal". Neste lago, a soda (carbonato de sódio, $\mathrm{Na}_{2} \mathrm{CO}_{3}$ ) se depositava nas margens do lago, resultado, segundo Berthollet, da reação entre o sal contido na água e o calcário (carbonato de cálcio, $\mathrm{CaCO}_{3}$ ) do fundo do lago. Berthollet explicou o fenômeno apelando para uma dupla circunstância: a quantidade de sal e de calcário, e o fato de os dois produtos da reação serem continuamente eliminados do meio reacional, sendo o cloreto de cálcio drenado através do solo e o carbonato de sódio precipitado nas margens do lago.

Essa reação ocorre no sentido oposto ao verificado no laboratório:

no lago: $2 \mathrm{NaCl}+\mathrm{CaCO}_{3} \rightarrow \mathrm{Na}_{2} \mathrm{CO}_{3}+\mathrm{CaCl}_{2}$

no laboratório: $\mathrm{Na}_{2} \mathrm{CO}_{3}+\mathrm{CaCl}_{2} \rightarrow 2 \mathrm{NaCl}+\mathrm{CaCO}_{3}$ 
Isso levou Berthollet a uma inversão sistemática dos juízos que norteavam o trabalho experimental do químico newtoniano. Se, para Bergman, o meio reacional (temperatura, concentração) era uma fonte de interferência que permitia explicar as anomalias, para Berthollet, todas as reações são incompletas e, agora, era necessário explicar as reações completas, através de fatores específicos, como a eliminação do produto, por sua baixa solubilidade, ou por sua alta volatilidade ${ }^{6}$.

Para Berthollet, a direção de uma reação não era um absoluto, sendo determinada pelas atrações existentes no meio reativo. Em sua Estática Química (1803), Berthollet recusou a distinção entre afinidades de agregação e afinidades de combinação, afirmando que: "Toda reação química entre duas substâncias [...] forma, ou tende a formar, entre elas, uma união [...]. Chama-se combinação tanto o resultado desta união, como o processo mesmo da dita união (citado por Lespieau. La Molécula Química, p. 25). Para ele, a força newtoniana de atração não permitia distinguir entre as forças físicas (agregação) e as forças químicas (composição).

Essa recusa em distinguir as afinidades químicas das afinidades mecânicas decorre de sua rejeição da idéia das atrações eletivas, por serem fixas e por indicarem apenas um sentido para a reação. Para Berthollet, uma reação não tinha uma "direção natural"; a direção era determinada pelas condições do meio, ou seja, as atrações não eram eletivas, mas relacionais.

Assim, a maneira como as reações incompletas se transformaram de uma anomalia, para Bergman, em uma regra, para Berthollet, constitui um bom exemplo daquilo que Kuhn denominou de mudança paradigmática.

Finalizo esta seção afirmando que, de qualquer modo, a química newtoniana representou uma das principais linhas de pesquisa na ciência química do século XVIII, fazendo avançar a compreensão da estrutura química do mundo, fundamentada por um quadro teórico singular.

\section{A SÍNTESE LAVOISIERIANA}

Afirmamos anteriormente que o pensamento newtoniano chegou à problemática da química tradicional através de questão 31 da Óptica. Afirmamos também que a incursão newtoniana pela ciência química poderia ser lida de duas maneiras: uma, reduzindo a química a um ramo da física; outra, oferecendo à tradição uma metodologia capaz de tornar o trabalho sobre as transformações materiais em uma ciência dedutiva, como a astronomia.

Cabe discutir um pouco mais a origem dessas interpretações. $\mathrm{Na}$ verdade, elas provêm do próprio Newton. Isto porque ele mesmo associou duas tradições de pesquisa que abrangiam universos de interesses diferentes.

Nos Principia, Newton tratou da ciência do movimento, das leis matemáticas que regiam o movimento dos astros, leis fundamentadas em princípios que, segundo ele, eram inerentes aos próprios corpos, como a extensão, a impenetrabilidade, a inércia, o peso, etc. e na constante ação divina sobre a Natureza, ação sentida através da gravidade.

Os Principia deram origem a um campo de pesquisa que durante o século XVIII foi chamado de física geral (physique générale). Eram estudos altamente matematizados, nos quais Lagrange, Euler, d'Alembert, Laplace e outros procuravam provar a universalidade da gravidade, a estabilidade do universo e afastar a necessidade de admitir a ação do divino no universo. A primeira leitura da incursão de Newton pela química foi própria dessa tradição de pesquisa ${ }^{8}$.

Porém, Newton também se ocupou do estudo dos fenômenos que envolviam as transformações materiais, fenômenos próprios de uma física especial (physique particulière). Na Óptica, Newton estava interessado em estudar as propriedades da óptica, da eletricidade, do magnetismo, das transformações químicas, etc. Nesse estudo, Newton atribuiu as transformações que ocorriam no microcosmo a causas semelhantes àquelas envolvidas nas transformações macroscópicas.

Isso fez com que muitos químicos procurassem fundamentar suas práticas experimentais em uma metodologia newtoniana, descrevendo reações que, tradicionalmente, singularizavam uma substância, como simples relações entre corpos químicos, relações que poderiam ser matematizadas, tornado-se passíveis de ser deduzidas a priori.

Assim, com os Principia e a Óptica, Newton tanto implantou sua metodologia às "ciências clássicas", quanto àquelas ciências de tradição baconiana, como a química. Os Principia serviram de referência para os trabalhos voltados para o estudo da mecânica celeste, da hidráulica, da teoria das vibrações, da forma dos astros, do fenômeno das marés, etc. A Óptica, por sua vez, foi base para o desenvolvimento de uma tradição experimental pouco matematizada, abrangendo os fenômenos ópticos, elétricos, magnéticos, e químicos.

À química, como visto antes, interessava a questão 31, que foi aceita enquanto uma interpretação empírica de algumas reações particulares. Porém, houve resistência da parte dos químicos tradicionais quanto à adoção das conseqüências epistemológicas da metodologia newtoniana. Para os newtonianos, os corpos, em si mesmos, eram inertes, desprovidos de qualquer qualidade singular, idéia totalmente rejeitada pelos químicos comprometidos em defender uma singularidade para a sua ciência.

Uma tentativa de solucionar esse conflito foi defendida por Macquer, que aceitava a ordenação de acordo com a reatividade, mas rejeitava a idéia de que os corpos fossem inertes, atribuindo-lhes princípios singulares. Contudo, a melhor síntese entre os dois programas foi oferecida por A. Lavoisier (1743-1794), que se propunha a adequar o empirismo baconiano a uma metodologia inspirada em Newton. Nota-se esta tentativa de harmonização no Discurso Preliminar do Tratado $^{17-21}$, no qual Lavoisier considerou que o empirismo baconiano deveria ser guiado por uma metodologia newtoniana, apreendida na obra do filósofo E. B. de Condillac (1714-1780) $)^{22,23}$. No entanto, apesar de reconhecer a metodologia newtoniana, Lavoisier admitia a existência de princípios portadores de qualidade; princípios como o do oxigênio (princípio acidificante), do calórico (princípio do fogo), do hidrogênio (princípio formador de água), que serviam para garantir um território próprio ao trabalho dos químicos.

No Tratado, Lavoisier fez convergir interesses antagônicos, oferecendo uma teoria química com padrões metodológicos semelhantes aos das ciências clássicas, e preservando uma identidade para a ciência química. Esse foi, sem dúvida, um dos motivos da ampla aceitação de suas idéias. Não bastasse isso, Lavoisier se associou a P-S. Laplace (1749-1827), um acadêmico que voltava seus estudos principalmente para os fenômenos da Física Geral, que estava, porém, muito interessado em expandir a matemática da física celeste aos fenômenos da física especial ${ }^{4}$.

O interesse em quantificar o princípio do calórico uniu Lavoisier a Laplace uma empreitada na qual compartilhavam o objetivo principal - medir o calor -; porém, divergiam quanto à natureza desse fluido, tanto é que não discutiram a natureza do calor, atendo-se à descrição do aparelho de medir o calor - o calorímetro - e à matematização dos dados experimentais ${ }^{24}$.

Na dissertação apresentada à Academia em 1783 (Dissertação sobre o Calor), Lavoisier estava interessado em tornar mensurável o calórico, um dos princípios de sua química, adotando uma concepção de calor derivada da tradição dos químicos, notadamente de J. Black (1728-1799). Laplace, por sua vez, estava interessado em medir as forças envolvidas nas transformações microscópicas, considerando que o calórico era responsável pelas forças repulsi- 
vas que atuavam nesse universo. Sua concepção de calor seguia a da física geral, para a qual o calor era resultado do movimento das partículas.

Esta parceria entre Lavoisier e Laplace rendeu ao primeiro uma clara demonstração de que o princípio do calórico, embora de causa desconhecida, suplantava em clareza a interpretação flogística do fogo. Para o segundo, representou o ponto de partida de seu estudo sobre as forças intermoleculares e sobre as afinidades químicas, concebidas por ele, como forças de atração. Aliás, Laplace compreendia as afinidades da mesma forma que Berthollet, e se considerarmos que Berthollet foi um dos principais colaboradores de Lavoisier, os ideais newtonianos de Lavoisier se tornam evidentes.

Apesar disso, Lavoisier não se referiu às afinidades no seu Tratado, por considerar que os conhecimentos sobre esse tema requeriam novas experiências, apesar de considerar ser esta a parte da química mais suscetível de torna-se uma ciência exata. Essa recusa de Lavoisier em incluir um estudo sobre as afinidades químicas em seu Tratado indica seu forte compromisso com a tradição baconiana, de não conjecturar sobre aquilo a cujo respeito os fatos se calam. Ou seja, embora partilhasse dos ideais metodológicos proclamados pelos newtonianos, Lavoisier não criou um programa newtoniano de pesquisa, ao contrário de seus colaboradores mais próximos, os newtonianos Guyton de Morveau e Berthollet.

A controvérsia entre os químicos newtonianos e aqueles ligados a uma tradição stahliana não se encerrou com Lavoisier, estendendo-se até as primeiras décadas do século XIX, tendo na disputa entre o newtoniano Berthollet e o stahliano Proust seu ponto máximo. Contudo, a síntese epistemológica de Lavoisier demonstra o que estava em jogo na incursão do pensamento newtoniano pela química ${ }^{25}$.

\section{CONCLUSÃO}

Consideramos que nosso trabalho histórico-epistemológico pode contribuir com os esforços feitos no sentido de aprimorar as ferramentas empregadas no ensino de química. Isto porque uma investigação com vistas a descrever a epistemologia utilizada na produção de um conhecimento do passado é essencial para melhor compreensão das formas atuais de produção e assimilação de conhecimento.

Obviamente, não se trata de procurar explicações para o atual conhecimento químico em alguma tradição do passado, o que caracteriza aquilo que Bachelard chamou de 'obstáculo epistemológico'26. Uma historiografia de caráter epistemológico não tem por objetivo apresentar qualquer linearidade no desenvolvimento da ciência, mas o de descrever os processos de produção de conhecimento emprega- dos em diferentes épocas pelos praticantes de uma determinada disciplina científica.

É essa historiografia que julgamos ser de extrema importância na otimização das práticas pedagógicas. Com ela, ampliam-se os nexos entre o conhecimento químico e outros interesses humanos, de modo a termos uma compreensão mais aprofundada dos cânones epistêmicos da ciência química, dos processos de produção desses cânones, das relações interdisciplinares, além das implicações sociais do conhecimento químico.

\section{REFERÊNCIAS}

1. Rossi, P.; O nascimento da ciência moderna na Europa, EDUSC: São Paulo, 2001.

2. Newton, I.; Óptica, EDUSP: São Paulo, 1996.

3. Newton, I.; Textos, Antecedentes e Comentários, escolhidos por I. Bernard Cohen e Richard S. Westfall, Ed. da UERJ: Rio de Janeiro, 2002.

4. Scerri, E.; J. Chem. Educ. 2000, 77, 522.

5. Scerri, E.; Mcintyre, L.; Synthesis 1997, 111, 213.

6. Stengers, I. Em Elementos para uma História da Ciência; Serres, M., org.; Terramar: Lisboa, 1996, vol. II, cap. V.

7. Bensaude-Vincent, B.; Stengers, I.; História da Química, Instituto Piaget: Lisboa, 1996, p. 75, 77, 102 .

8. Abrantes, P.; Imagens de Natureza, Imagens de Ciência, Papirus: São Paulo, 1988, p. 78, 143-173.

9. Maar, H. J.; Pequena História da Química, parte I, Ed. Papa-Livro: Florianópolis, 1999.

10. Quine, W.; Os Pensadores, Ed. Nova Cultural: São Paulo, 1989.

11. Kant, I.; Crítica da Razão Pura, Fundação Calouste Gulbenkian: Lisboa, 1997.

12. Filgueiras, C. A.; Quim. Nova 1995, 18, 219.

13. Filgueiras, C. A.; Lavoisier - o estabelecimento da química moderna, Ed. Odysseus: São Paulo, 2002.

14. Kuhn, S. T.; A Estrutura das Revoluções Científicas, Ed. Perspectiva: São Paulo, 1975.

15. Stengmüller, W.; A Filosofia Contemporânea, EDUSP: São Paulo, 1977

16. Kuhn, S. T.; A Tensão Essencial, Edições 70: Lisboa, 1989, caps. XII.

17. Lavoisier, A.; Traité Élémentaire de Chimie, Gauther-Villar Éditeur: Paris, 1937.

18. Bensaude-Vincent, B.; Lavoisier, Flammarion: Paris, 1993.

19. Berthelot, M.; Una Revolución en la Química, Lavoisier, Editorial Losada: Buenos Aires, 1945.

20. Bensaude-Vincent, B. Em ref. 6, vol. II, cap. VIII.

21. Tosi, L.; Quim. Nova 1989, 12, 33.

22. Condillac, B. E.; Tratado dos Sistemas; Lógica e Resumo selecionado do Tratado das Sensações, Coleção Os Pensadores, Abril Cultural: Rio de Janeiro, 1973.

23. Condillac, B. E.; Traité des Sensations, Fayard: Paris, 1984.

24. Chagas, A.; Quim. Nova 1992, 15, 269.

25. Mocellin, C. R.; Dissertação de Mestrado, Universidade Federal de Santa Catarina, Brasil, 2003.

26. Bachelard, G.; Epistemologia, 2a ed., Zahar Eds.: Rio de Janeiro, 1977. 